\title{
IONIZATION DELOCALIZATION AND ALCHEMI OF B2-ORDERED ALLOYS
}

\section{M. Anderson and J. Bentley}

Metals \& Ceramics Division, Oak Ridge National Laboratory, P.O. Box 2008, Oak Ridge, TN 37831

Recent formulations of the ALCHEMI technique have explicitly accounted for ionization delocalization of an element $i$ with a single linear parameter $L_{i}$ that represents the extent of localization.1,2 The x-ray emission of a spectral line characteristic of the element is assumed to be proportional to a linear combination of the thickness-averaged electron intensity at (1) the site of the atom (fraction: $L_{i}$ ) and (2) averaged over the unit cell (fraction: $\left(1-\mathrm{L}_{\mathrm{i}}\right)$ ). The parameter $\mathrm{L}_{\mathrm{i}}$ is assumed to be characteristic of the elemental shell and independent of the diffracting conditions. In consequence of these assumptions, it has been shown that ionization delocalization correction can be performed in conjunction with "statistical" ALCHEMI by correcting only the extracted correlation coefficients. ${ }^{2}$

The parameter $r_{i}(\xi)=\mathrm{I}_{\mathrm{i}}(\xi) / \mathrm{I}_{\mathrm{i}}(0)$ is defined to be the ratio of the characteristic intensity (I) of element $\mathrm{i}$ at a crystal orientation $(\xi)$ to its characteristic intensity at a reference orientation $(0)$, which is ideally free of electron channeling effects. Coefficients $\alpha_{k j}$ correlating the r-values of each alloying element $k$ with those of the $n$ host elements $j$ are extracted using multivariate analysis following Rossouw et al., 3

$$
\mathrm{r}_{\mathrm{k}}=\sum_{\mathrm{j}=0}^{\mathrm{n}} \alpha_{\mathrm{kj}} \mathrm{r}_{\mathrm{j}} \text {, }
$$

except with an additional coefficient $\alpha_{\mathrm{k} 0}$ to account for the delocalized fractions of each element, with $\mathrm{r}_{0} \equiv 1 .{ }^{1}$ The correlation coefficients can be corrected for ionization delocalization with the relation: ${ }^{2}$

$\chi_{k j}=\frac{L_{j}}{L_{k}} \alpha_{k j} \equiv L_{j k} \alpha_{k j}$.

These corrected coefficients equal the fractional occupancies $p_{k j}$ of alloying element $\mathrm{k}$ on site $\mathrm{j}$ if the host elements are perfect markers for their respective sites. Whether the host elements are perfect markers or not, the sum of $\chi_{\mathrm{kj}}$ over all sites $\mathrm{j}$ should equal unity, just as the site occupancies sum to unity. The purpose of the present paper is to demonstrate that the major assumption underlying this formulation is justified: that the degree of ionization localization of an elemental shell can be accounted for by a linear coefficient; and to introduce a potential method, which would be applicable to B2-ordered alloys, of independently extracting the ratio of coefficients $L_{j k}$ necessary for delocalization correction.

For B2-ordered alloys, the major low-index planes are $\{110\}$ and $\{200\}$. The $\{110\}$ planes are of equal composition: for a stoichiometric alloy $\mathrm{AB}$, the composition of each $\{110\}$ plane is $\mathrm{AB}$ (Fig. 1). Conversely, the two crystallographic sites are completely separated on alternating $\{100\}$ planes and have alternating compositions A and B in a fully ordered alloy. When dynamical diffracting conditions are set up at these two systematics orientations, $\{200\}$ should provide good discrimination between the ' $A$ ' and 'B' sites of the crystal and $\{110\}$ none at all, as long as contributions from nonsystematic reflections are insignificant. Ionization delocalization should influence the variation of the characteristic $\mathrm{x}$-ray intensities at both planar channeling conditions. However, at the $\{110\}$ systematics orientation, the effect of ionization delocalization should be isolated.

A Cr-doped $\mathrm{FeAl}$ alloy of nominal composition $\mathrm{Fe}_{60} \mathrm{Al}_{35} \mathrm{Cr} 5$ and a series of $\mathrm{Fe}$-doped $\mathrm{NiAl}$ alloys with between 0.25 and 12 at.\% Fe were analyzed for this study. Energy-dispersive X-ray (EDX) spectra were acquired with a Philips CM12 operated at $120 \mathrm{kV}$ equipped with an EDAX 9900 spectrometer and superUTW $\mathrm{Si}(\mathrm{Li})$ detector. The variation of r-values of the host elements $\mathrm{Fe}$ and $\mathrm{Al}$ relative to that of the alloying element $\mathrm{Cr}$ is shown in Fig. 2 for spectra acquired near $<117>$ beam direction at a range of $\{110\}$ excitations between the symmetry and the $\{220\}$ Bragg orientations. The slopes of these lines, which are the ratios $L_{j k}$ for the $\{110\}$ systematics orientation, are shown in Fig. 2. These values, which indicate that $\mathrm{Fe}$ is slightly more localized and $\mathrm{Al}$ substantially less localized than $\mathrm{Cr}$, are plausible. The excellent linearity of the data substantiates the use of linear coefficients to model ionization localization.

DISTRIBUTION OF THIS DOCUMENT IS

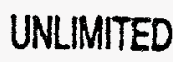

UNLIMITED

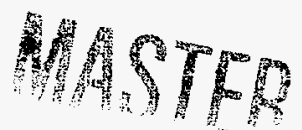
"The submitted manuseript has been
authored by a contrector of the U.S.
Government inder contract No. DE-
ACO5-84OR2 1400. Accordingly. the U.S.
Government retains a nonexchusive,
royalty-free license to publish or reproduce
the publiched form of this contribution, or
allow others to do so. for U.S. Government 
Furthermore, it has been investigated whether the $\mathrm{L}_{\mathrm{jk}}$ acquired at a $\{110\}$ systematics orientation could be accurately applied to ALCHEMI data acquired at $\{200\}$. Other studies have indicated that the degree of localization varies with interplanar spacing, and that this variation may be strong for lower energy ionizations such as Al K. ${ }^{4}$ Correlation coefficients $\alpha_{\mathrm{kj}}$ acquired at $\{200\}$ were corrected with $\mathrm{L}_{\mathrm{jk}}$ ratios determined at $\{110\}$, as indicated by equation (2). This method yields independent $\chi_{\mathrm{kj}}$, and one can check to ensure that their sum, $\Sigma \equiv \chi \mathrm{CrFe}+\chi \mathrm{CrAl}$, is unity. It would be expected that a significant difference in $L_{A l}$ between $\{110\}$ and $\{200\}$ would effect a significant deviation of $\Sigma$ from unity, particulary for alloys in which the alloying element resides predominantly on the 'Al'-site. This test was performed by applying the $L_{j k}$ ratios in Fig. 2 to ALCHEMI data acquired from the $\mathrm{Cr}$-doped $\mathrm{FeAl}$ specimen near $<014>$ beam direction at a range of $\{200\}$ excitations between symmetry and the $\{400\}$ Bragg position. The result is $\Sigma=1.04 \pm 0.03$. Similarly, localization coefficients $L_{j k}$ were extracted from an alloy of stoichiometry $\mathrm{Ni}_{50} \mathrm{Al}_{40} \mathrm{Fe}_{10}$ and applied to the correlation coefficients of a series of sixteen Fe-doped NiAl alloys. The result of this more extensive study is $\langle\Sigma\rangle=1.01 \pm 0.01$. Also, there was no measurable variation in the $\Sigma$ values with site-occupancy. These results seem to be in better agreement with similar $L_{j k}$ for the $\{110\}$ and $\{200\}$ systematics orientations than with $L_{j k}$ that vary significantly with interplanar spacing. The outlined method for delocalization correction would allow accurate ALCHEMI analyses that are free from reliance on adjustable parameters. 5

\section{References}

1. M.G. Walls, Microsc. Microanal. Microstruct. 3(1992)443.

2. I.M. Anderson and J. Bentley, Proc. 13 ${ }^{\text {th }}$ ICEM: Electron Microscopy 1994 1(1994)609.

3. C.J. Rossouw et al., Phil. Mag. Lett. 60(1989)225.

4. S.J. Pennycook, Ultramicroscopy 26(1988)239.

5. This research was supported by the Division of Materials Sciences, U.S. Department of Energy, under contract DE-AC05-84OR21400 with Martin Marietta Energy Systems, Inc. This work was also partially supported by an appointment (IMA) to the Oak Ridge National Laboratory Postdoctoral Research Associates Program, which is administered jointly by the Oak Ridge Institute for Science and Education and Oak Ridge National Laboratory.

1

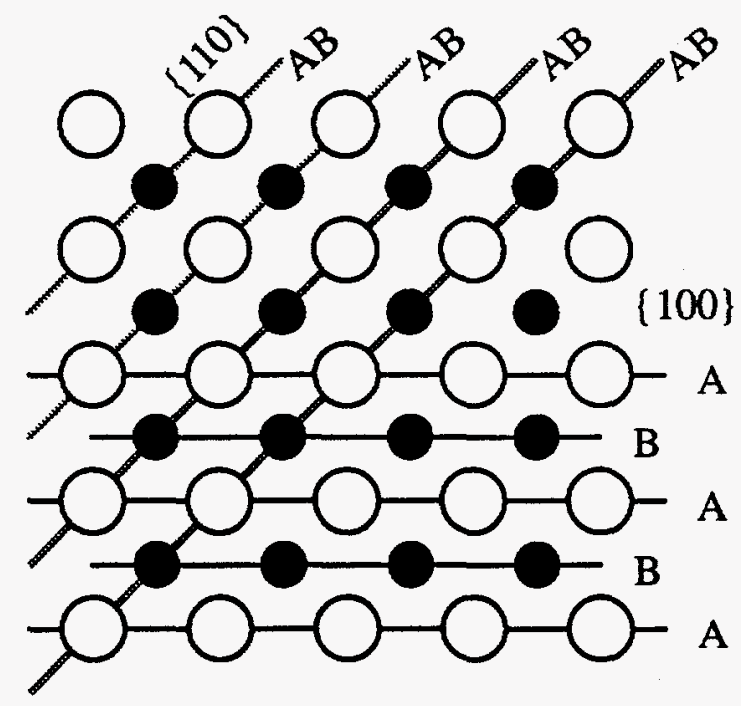

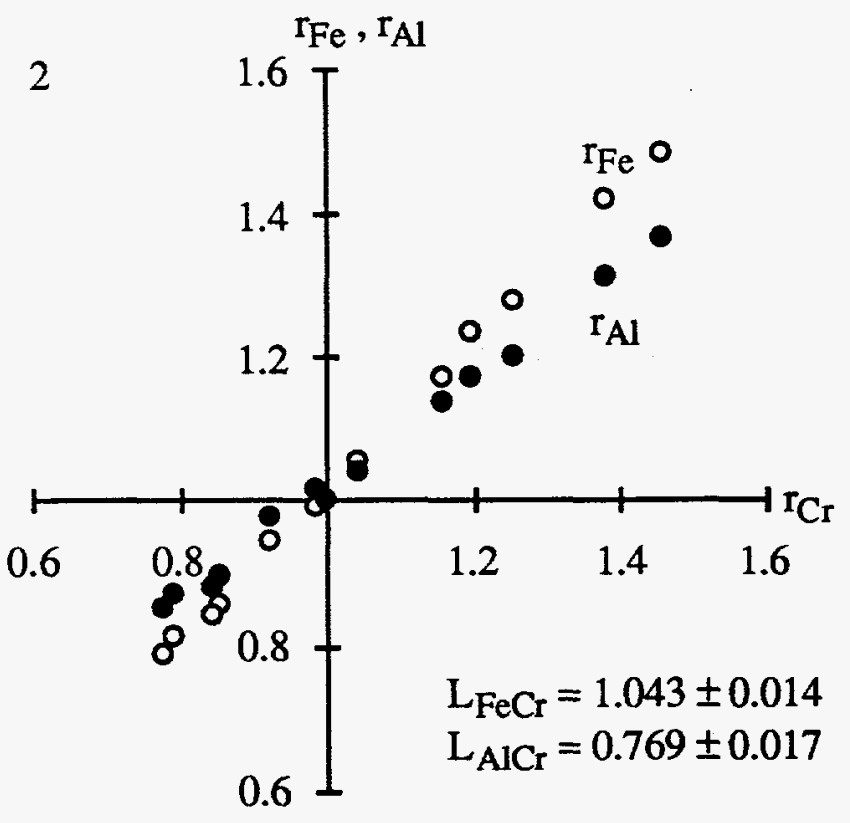

FIG. 1. Schematic representation of a B2-ordered alloy "AB" viewed along $<001>$.

FIG. 2. Variation of the intensity ratios of the host and alloying elements in $\mathrm{Cr}$-doped FeAl for $\{110\}$ systematics orientation. The values $\mathrm{L}_{\mathrm{jk}}$ are the slopes of the linear regression fits to the data. 


\section{DISCLAIMER}

This report was prepared as an account of work sponsored by an agency of the United States Government. Neither the United States Government nor any agency thereof, nor any of their employees, makes any warranty, express or implied, or assumes any legal liability or responsibility for the accuracy, completeness, or usefulness of any information, apparatus, product, or process disclosed, or represents that its use would not infringe privately owned rights. Reference herein to any specific commercial product, process, or service by trade name, trademark, manufacturer, or otherwise does not necessarily constitute or imply its endorsement, recommendation, or favoring by the United States Government or any agency thereof. The views and opinions of authors expressed herein do not necessarily state or reflect those of the United States Government or any agency thereof. 


\section{DISCLAIMER}

Portions of this document may be illegible in electronic image products. Images are produced from the best available original document. 